Epistemologi Tafsir Klasik: Studi Analisis ....

\title{
EPISTEMOLOGI TAFSIR KLASIK: STUDI ANALISIS PEMIKIRAN IBNU KATSIR
}

\author{
Wely Dozan \\ Program Pasca Sarjana \\ Jurusan Aqidah dan Filsafat Islam Konsentrasi Studi Qur'an dan Hadits \\ Universitas Islam Negeri Sunan Kalijaga Yogyakarta \\ welydozan77@gmail.com
}

\begin{abstract}
Abstrak
Epistemologi pada dasarnya adalah salah satu cabang ilmu filsafat yang mengkaji tentang akar pemikiran dan konsep dasar pengatuhan. Konsep tersebut memiliki paradigma yang melahirkan sebuah gagasan dalam proses pemikiranya. Hal tersebut menunjukkan adanya epistemologi yang digunakan oleh mufassir klasik yaitu Ibnu Katsit dalam memahami dan menjelaskan ayat-ayat al-Qur'an secara panjang dan luas. Karena penafsiran tersebut jika dicermati dan di telaah kritis kembali akan ditemukan secara komprehensif arah pemikirannya dalam menafsirkan al-Qur'an. Oleh karenaya, tulisan ini hadir untuk mengungkapkan dan memetakan secara signifikan epistemologi pemikiran Ibnu Katsir dalam proses penafsiran tersebut. Dengan demikian dapat disimpulkan, sumber pengetahuan dalam penafsirannya mengandung dua klasifikasi secara garis besar yaitu: Pertama. Tafsir Bil Ma'tsur. Kedua, Tafsir Al-Ra'yi. Adapun tafsir bil matsur terbagai menjadi empat penafsiran yaitu, tafsir al-Qur'an dengan al-Qur'an, tafsir al-Qur'an dengan hadis, tafsir al-Qur'an dengan sahabat, dan tafsir al-Qur'an dengan pendapat para tabi'in. sedangkan tafsir Al-Ra'yi sebagai rasional yang didukung dengan ilmu pengetahuan kaidah-kaidah bahasa untuk mengungkap makna sacara sitematis. Pendek kata, penulis akan memberikan kontribusi secara jelas bagaimana epistemologi metodolgi penafsiran alQur'an yang dilakukan Ibnu Katsir Tersebut.
\end{abstract}

Kata kunci: Epistemologi, Metodologi, Ibnu Katsir.

\begin{abstract}
Epistemology is basically a branch of philosophy that studies the roots of thought and basic concepts of submission. The concept has a paradigm that gives birth to an idea in the process of thinking. This shows that there is an epistemology used by classical commentators, Ibn Katsir in understanding and explaining verses of the Qur'an in a lengthy and broad manner. Because of this interpretation if examined and critically examined again will be found in a comprehensive direction of thought in interpreting the Qur'an. Therefore, this paper is here to express and map significantly the epistemology of Ibn Katsir thought in the interpretation process. Thus it can be concluded, the source of knowledge in the interpretation contains two broad classifications, namely: First. Tafsir Bil Ma'tsur. Secondly, Tafsir Al-Ra'yi. The interpretation of bil matsur is divided into four interpretations, namely, the interpretation of the Qur'an with the Qur'ran, the interpretation of the Qur'an with the Hadith, the interpretation of the Qur'an with friends, and the interpretation of the Qur'an with the opinion the tabi'in. while the interpretation of $A l-R a^{\prime} y i$
\end{abstract}

Falasifa, Vol. 10 Nomor 2 September 2019| 147 
Wely Dozan

as rational is supported by the science of the rules of language to reveal the meaning of sitematic ceremony. In short, the author will make a clear contribution on how the epistemology of the Qur'anic interpretation is carried out by Ibn Katsir.

Keywords: Epistemology, Tafsir, Ibn Katsir.

\section{PENDAHULUAN}

Berangkat dari al-Qur'an sebagai kitab suci kaum muslim dan menjadi sumber ajaran Islam yang pertama dan utama yang harus mereka imani dan aplikasikan dalam kehidupan. ${ }^{1}$ Hal ini menunjukkan adanya kajian terkait dengan penafsiran ayat-ayat al-Qur'an. Munculnya kajian $\operatorname{tafsir}^{2}$ disebabkan karena menjelaskan dan mendalami makna-makna yang terkandung dalam al-Qur'an secara lebih detail, baik dari segi himkah, pesan moral, hukum-hukumnya, maupun nilai-nilai etik universal yang ada didalamnya. ${ }^{3}$

Perkembangan keilmuan dalam karya tafsir menyebabkan terjadinya keragaman metode dan corak penafsiran. Seiring dengan muncul metode tahlili (analitis) yang memberikan ruang lingkup yang luas bagi seseorang mufassir untuk menuangkan segala ide yang ada dalam pikiranya semata-mata untuk menghasilkan makna yang termuat dalam teks ayat al-Qur'an. Tradisi kajian, pemahaman, dan penafsiran al-Qur'an telah berkembang dalam ilmu atau metode, misalnya 'Ulumul Qur'an, Ulum al-Tafsir, Tafsir, dan Ta'wil, baik dalam dominasi studi tekstual maupun studi kontekstual. Dalam perkembanganya, ilmu dan metode kajian al-Qur'an tersebut selalu dinamis atau tidak statis. $^{4}$

\footnotetext{
${ }^{1}$ H.A. ATHILlAH, Sejarah al-Qur'an, Verifikasi Tentang Ptensitas al-Qur'an, (Yogyakarta: Pustaka Pelajar, 2010), hlm. 1

${ }^{2}$ Kajian Tafsir terkait dengan kandungan pemikiran dan metode berpikir yang mendasarinya dapat melahirkan dua aspek terhadap pemikiran para mufassir yaitu, kandungan penafsiran yang merupakan produk berpikir penafsir, dan metode penafsiran yang merupakan cara yang ditempuh penafsiran dalam menafsirkan Al-Qur'an, baik yang terkait dengan dengan bentukya seperti tafsir dengan riwayat dan tafsir dengan nalar, metodenya seperti tahlili, ijmali, dan mawdhu'i maupun corak lainya. Dalam perkembagan tafsir Al-Qur'an tentu saja berangkat dari perkembangan pemikiran tentang metodologi tafsir Al-Qur'an karena metodologi tafsirlah yang melahirkan produk penafsiran Nabi Muhammad Saw yang disebut sebagai (al- tafsir al nabawi)

${ }^{3}$ Abdul Mustaqim, Metode Penelitian Al-Qur'an dan Tafsir, (Yogyakarta: Idea Press, 2015), hlm. 12.

${ }^{4}$ Yayan Rahtikawati, Dadan Rusma, Metodologi Tafsir Al-Qur'an (Strykturalisme, Semantik, Semiotik, \& hermeneutic, ( Bnadung: Pustaka Setis, 2013), hlm. 69
}

Falasifa, Vol. 10 Nomor 2 September 2019| 148 
Hal tersebut menunjukkan adanya usaha para mufassir dalam menggali dan mengetahui hakikat dalam penafsinya. Adapun salah satu tujuan penafsiran memang untuk menjelaskan kandungan makna ayat al-Qur'an. ${ }^{5}$ Namun hal ini tidak pernah terlepas dari pengetahuan yang dimiliki oleh mufassir karena (epistemology) ${ }^{6}$ pengetahuan perlu didukung dalam menafsirkan ayat al-Qur'an. Karena pengetahuan dapat memberikan suatu pemahaman yang secara sitematis dalam penafsiran ayat al-Qur'an.

Sejarah mencata bahwa, metode paenafsiran para ulama dapat dikatagorikan menjadi beberapa metode yang digunakan oleh mufassir diantaranya, Pertama, metode Ijmali, Kedua, metode Tahlili, Ketiga, metode Muqarran, Keempat, metode Tematik. ${ }^{7}$ Melihat perkembangan tafsir dari zaman klasik memiliki pradigma-pradigma dalam semua disiplin ilmu termasuk tafsir memiliki asumsi yang akan dipergunkan dalam menganalisisnya sebagaimana dikikutip Ian Barbaur, menurut Thomas Kuhn dalam The Structure of Scirntific Revolution, bahwa teori dalam sains tergantung pradigma. Perkembangan sebuah ilmu sangat dipengaruhi oleh perkembangan sebuah pradigma, demikian halnya dengan dengan ilmu-ilmu yang lain, termasuk di dalamnya paradigma tafsir yang dikembangakan di era-modern sampai kontemporer yang memiliki asumsi-asumsi dan corak-corak yang berbeda dengan tafsir pada era sebelumnya. ${ }^{8}$

Dari sinilah sejarah penafsiran al-Qur'an menemukan momentumnya dalam arti para pengkaji al-Qur'an untuk mencurahkan segenap pemikiran dan kemampuan analisisnya dalam melahirkan berbagai macam koncep dan ciri khas tersendiri dalam

\footnotetext{
${ }^{5}$ Abdul Mustaqim, Metode Penelitian Al-Qur'an dan Tafsir, (Yogyakarta: Idea Press, 2018), hlm 12

${ }^{6}$ Epistemologi: dapat diartikan sebagai knowlodge atau pengetahuan dan logy berarti teori. Oleh karena itu epistemologi sebagai teori pengetahuan. Adapun defenisi epistemologi merupakan cabang filsafat yang membahas hakikat ilmu pengetahuan manusia, sering diidentikkan dengan sebuah asumsi-asumsi teoritis yang mendasari suatu pendapat ataupun bangunan pengetahuan yang dimiliki setiap manusia. Lihat Prof.Dr. Juhaya Aliran-Aliran Filsafat dan etika hal.2 dan juga Drs Ayi Sopyan, Kapita Selekta Filsafat, hlm. 212.

${ }^{7}$ Pertama, Metode Ijmali (global) merupakan metode tafsir yang dalam menjelaskan ayat al-Qur'an bersifat global. Jadi yang dijelaskan adalah pesan-pesan pokok dari ayat yang di tafsirkan dan seseorang penafsir uraian yang bertele-tele. Kedua Metode Tahlili (analitis) merupakan metode tafsir yang mencoba menjelaskan ayat al-Qur'an secara analisis, berbagai aspek yang terkait dengan ayat al-Qur'an. Misalnya, dalam konteks asbabun nuzul (konteks turunya sebuah ayat), aspek munasabah, (keterkaitan ayat yang satu dengan ayat lain, atau keterkaitan tema dengan tema lainya. Ketiga, metode muqarran perbandingan yaitu metode tafsir yang dalam menjelaskan ayat-ayat al-Qur'an dengan membandingkan antara pendapat satu tikoh dengan tokoh lainya dalam satu atau beberapa ayat yang ditafsirkan. Keempat, metode tematik maudhu'I merupakan metode menafsirkan dengan mengambil tema tertentu, lalu mengumpulkan ayat-ayat yang terkait dengan tema tersebut. Baca selengkapnya, Abdul Mustaqim, Metode penelitian Al-Qur'an dan Tafsir, (Yogyakarta: Idea Press, 2015), hlm.17-19

${ }^{8}$ Abdul Mustaqim, Dinamika Sejarah Tafsir Al-Qur'an (Studi Aliran-aliran Tafsir dari Periode Klasik, Pertengahan hingga Moderen-Kontemporer), (Yogyakarta: Ida Press, 2016), hlm. 153.
}

Falasifa, Vol. 10 Nomor 2 September 2019 | 149 
Wely Dozan

menafsirkan ayat-ayat al-Qur'an. Para ulama dalam menafsirkan al-Qur'an melaui upaya menjelaskan makna-makna dari berbagai seginya kaitanya terhadap konteks historisnya maupun sebab-sebab turunya. ${ }^{9}$

Dengan demikian, tujuan dari penelitian epistemologi tafsir merupakan sebuah tinjauan analisis terhadap kitab tafsir ibnu katsir yang selama ini merupakan kitab tafsir yang penjelasanya secara terperinci. Namun penafsiran tersebut memiliki epistemology metode dalam menafsirkan ayat-ayat al-Qur'an. Lebih jauh lagi tulisan ini akan mengupas secara kritis bagaiman akar pemikiran Ibnu Katsir dalam menafsirkan al-Qur'an sehingga dalam penafsirannya memiliki metode dan uraian yang sangat panjang dalam memberikan suatu penafsiran terhadap ayat al-Qur'an.

\section{PEMBAHASAN}

\section{A. Latar Belakang Kelahiranya}

Sosok Ibnu Katsir adalah 'Imaduddin, Ismail bin Umar bin Katsir al-Bashri, alDimisqi, al-Faqih, al-Syafi'i. Beliau dilahirkan pada tahun 703 di Timur Bashri yang merupakan wilayah bagian Damaskus.ketika berusia dini, Ibnu Katsir sudah mulai kembara ilmiahnya. Di usia tujuh tahun ia mengunjungi Damaskus bersama saudaranya pada tahun 706. Ayahnya meninggal pada tahun 703 kala Ibnu Katsir masih belia. Kehidupanya kemudian dibantu oleh saudaranya. Seluruh waktunya dihabiskan untuk pengetahuan. Ia mengkaji, mempelajari, dan mengenal berbagai disiplin ilmu pengetahuan. ${ }^{10}$

Ibnu katsir melahirkan kitab yang pertama dan yang terkenal dalam sepanjang beberapa karya adalah Tafsir (al-Qur'anul adzim). Kitab ini merupakan kitab tafsir yang kajianya sangat luas cakupanya baik dari beberapa aspek keilmuan. Terkait dengan pembahasanya, kitab tersebut memiliki banyak memaparkan ayat-ayat yang bersesuaian maknanya dan perincian penjelasanya sangat panjang karena kitab tersebut merupakan kitab tafsir yang merupakan bentuk metode analisis dalam penafsiran. ${ }^{11}$

Adapun guru yang pernah beliau tekuni diantaranya: Syaikh Burhanuddin al-Fazari dan Kamaluddin bin Qadhi Syubhah, Ibnu Katsir mengokohkan keilmuanya terutama

\footnotetext{
${ }^{9}$ Rohimi, Metodologi Ilmu Tafsir dan Aplikasi Model Penafsiran, (Yogyakarta: Pustaka Pelajar, 2007), hlm.v

${ }^{10}$ Mani' Abd Halim Mahmud, Metodologi Tafsir “Kajian Komprehensif Metode Para Ahli Tafsir" (Jakarta: Raja Grafindo, 2006), hlm. 64

${ }^{11}$ Imam Ibnu Katsir, Tafsir Al-Qur'anul Adzim "Ibnu Katsir” Jilid 1, (Jawa Tengah: Insan Kamil, Cet-ke.4, 2017), hlm.v
}

Falasifa, Vol. 10 Nomor 2 September 2019| 150 
Epistemologi Tafsir Klasik: Studi Analisis ...

berbagai macam bidang disiplin keilmua misalnya ilmu hadits, membaca ushul hadis dengan al-Ashfani. Dapat dikatakan Ibnu Katsir merupakan tokoh mufassir klasik yang sangat akan luas ilmu pengetahuanya. ${ }^{12}$ Metodologi ini diterapkan Ibnu Katsir sebagai salah satu di antara sekian tafsir terbaik yang menjadi rujukan para pakar.

\section{B. Metodologi Tafsir Ibnu Katsir}

Sebelum melihat perkembangan epistemologi pengetahuan dalam tafsir Ibnu Katsir bahwa, hal yang perlu dikaji dan dicermati adalah Metode-metode yang digunakan dalam tafsirnya. Dalam kaitan ini, maka studi tafsir tidak terlepas dari metode., yakni suatu cara yang teratur dan terpikir baik-baik untuk mencapai pemahaman yang benar tentang apa yang dimaksudkan Allah di dalam ayat-ayat Al-Qur'an. Dapat diringkas bahwa, metode tafsie merupakan kerangka atau kaidah yang digunakan dalam menafsirkan ayat-ayat atau kaidah yang telah tertuang di dalam metode tersebut ${ }^{13}$. Dalam hal ini pemulis akan menelaah tafsir ayat al-Qur'an. Secara garis mengkaji tentang penafsiran "Ummatan Wasatan".

Dan demikian (pula) Kami telah menjadikan kamu (umat Islam), umat yang adil dan pilihan agar kamu menjadi saksi atas (perbuatan) manusia dan agar Rasul (Muhammad) menjadi saksi atas (perbuatan) kamu. Dan Kami tidak menetapkan kiblat yang menjadi kiblatmu (sekarang) melainkan agar Kami mengetahui (supaya nyata) siapa yang mengikuti Rasul dan siapa yang membelot. Dan sungguh (pemindahan kiblat) itu terasa amat berat, kecuali bagi orang-orang yang telah diberi petunjuk oleh Allah; dan Allah tidak akan menyia-nyiakan imanmu. Sesungguhnya Allah Maha Pengasih lagi Maha Penyayang kepada manusia.

Ibn Katsir ${ }^{14}$ menafsirkan bahwa yang dimaksud denga الوسط dapat diartikan sebagai pilihan yang terbaik, supaya di hari kiamat nanti kalian menjadi para saksi atas umat-umat

\footnotetext{
${ }^{12} I b d \ldots$, hlm. 64

${ }^{13}$ Nasaruddin Baidan, Metodologi Penafsiran Al-Qur'an, (Yogyakarta: Pustaka Pelajar, Cet-ke.III, 2005), hlm.2

${ }^{14}$ Ibn Katsir adalah ulama besar yang lahir di Basrah pada $700 \mathrm{H}$. Beliau adalah seorang ahli fiqih yang profesional, ahli hadits yang cerdas, sejarawan ulung dan seorang mufassir paripur na. Adapun karyakaryanya tersebar luas di berbagai negeri semasa hidupnya dan dimanfaatkan oleh orang banyak setelah wafatnya. Dan juga beliau memiliki karya dalam bidang tafsir secara utuh karena tafsir ini merupakan tafsir yang paling banyak memaparkan ayat-ayat yang bersesuaian maknanya, kemudian di ikuti denganpenafsiran ayat dengan hadits-hadits marfu' yang ada relevansinya dengan ayat-ayat yang ditafsirkan serta menjelaskan apa yang dijadikan hujjah dari ayat tersebut. Baca selengkapnya tafsir ibn katsir, hal. v
}

Falasifa, Vol. 10 Nomor 2 September 2019 | 151 
Wely Dozan

lainya, karena mereka semua mengakui keunggulan kalian, Quraisy adalah kabilah yang paling baim nasabnya Rasulullah Saw sendiri adalah orang wasath' di antara kaumnya. Maknanya beliau adalah sosok paling mulia nasabnya. ${ }^{15}$

Adapun sebab turunya tersebut yang termuat di dalam riwayat Ibnu Ishaq menuturkan: Ismail Khlaid menceritakan kepadaku, dari Abu Ishaq, dari Al-Barra, dia berkata "Dahulu Rasulullah Saw shalat menghadap ke arah Baitul Maqdis, ketika itu, beliau sering menengadahkan pandangan kea rah langit, menanti adanya perintah Allah Swt tentang pemindahan kiblat. Maka Allah Swt menurunkan firman-Nya yang artinya: “ Kami melihat wajahmu (Muhammad) sering menengadah ke langit, maka akan kami palingkan engkau ke kiblat yang engkau senangi. Maka hadapkanlah wajahmu kearah masjidil haram". Dan Ibnu Ishaq memiliki beberapa jalur periwayatan yang serupa. ${ }^{16}$

Imam Ahmad juga meriwayatkan, dari Abu Sa’id Al-Khudri, dari Nabi Saw, berkenaan

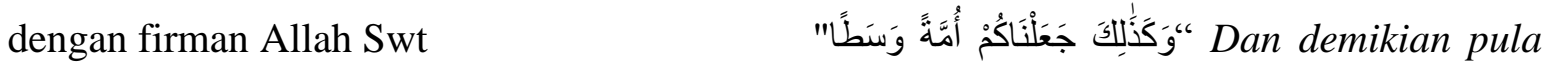
kami telah menjadikan kamu umat Islam umat yang adil dan pilihan"17. Hal ini sebagaiamana diriwayatkan dalam Ash-Shihain dan lainya. Manakala Allah Swt jadikan umat ini sebagai umat terbaik, Dia memberinya syari'at paling sempurna . sebagaimana Firman Allah Swt Surah Al-hajj.

"Dan berjihadlah kamu pada jalan Allah dengan Jihad yang sebenar-benarnya. Dia telah memilih kamu dan Dia sekali-kali tidak menjadikan untuk kamu dalam agama suatu kesempitan. (Ikutilah) agama orang tuamu Ibrahim. Dia (Allah) telah menamai kamu sekalian orang-orang Muslim dari dahulu, dan (begitu pula) dalam (Al Quran) ini, supaya Rasul itu menjadi saksi atas dirimu dan supaya kamu semua menjadi saksi atas segenap manusia, Maka dirikanlah sembahyang, tunaikanlah zakat dan berpeganglah kamu pada tali Allah. Dia adalah Pelindungmu, Maka Dialah Sebaik-baik pelindung dan sebaik- baik penolong.".

Imam Ahmad R.A. meriwayatkanya, dari Abu Sa'id Al-Khudri, ia berkata, Rasulullah Saw bersabda: Nabi Nuh A.S. dipangggil pada hari kiamat, lalu ditanya, “Apakah sudah kamu sampaikan? Ia pun menjawab, 'Sudah'. Kaumnya lantas dipanggil

\footnotetext{
${ }^{15}$ Imam Ibnu Katsir, Tafsir Al-Qur'anul Adzim "Ibnu Katsir" Jilid 1, (Jawa Tengah: Insan Kamil, Cet-ke.4, 2017), hlm. 6

${ }^{16}$ Imam As-Syuthi, Asbabun Nuzul Qur'an, Tahqiq: Syaikh Hafizh Syi'sya (Jawa Tengah: Insan Kamil, 2016), hlm. 45

${ }^{17} \mathrm{Ibd}$..., hlm. 7
}

Falasifa, Vol. 10 Nomor 2 September 2019| 152 
Epistemologi Tafsir Klasik: Studi Analisis ...

kemudian ditanya, 'Apakah ia (Nuh) sudah menyampaikan kepada kalian? Kaumnya menjawab, 'Tidak ada pemberi peringatan yang datang kepada kami, tidak ada seorang pun yang datang kepada kami' Nabi Nuh pun ditanya, Siapa saksimu? 'Ia menjawab, 'Muhammad dan umatnya '. Itulah firman Allah. 'Dan demikian (pula) Kami telah menjadikan kamu (umat Islam), umat yang adil dan pilihan'. Beliau berkatan, wasath adalah adil (H.R. Diriwayatkan oleh Al-Bukhari, At-Tirmidzi, An-Nas'I, dan Ibnu Majah). ${ }^{18}$

Melihat sekilas penafsiran Ibnu Katsir dalam menafsirkan ayat-ayat al-Qur'an terkait dengan penafsiran (Umatan Wasatan) secara analisis bahwa, metode penafsiranya diuraikan secara panjang lebar dalam konteks melihat asbabun nuzulnya dan sebagainya. Pendek kata Ibnu Katsir dalam tafsirnya menggunakan metode tahlili (analitis).berarti menjelaskan ayatayat al-Qur'an dengan cara meneliti semua aspeknya dan menyingkap seluruh maksudnya. ${ }^{19}$

Menurutnya, metodologi yang paling tepat digunakan dalam menafsirkan ayat-ayat alQur'an diantaranya sebagai berikut:

1. Menafsirkan Al-Qur'an denagn Al-Qur'an. ${ }^{20}$ Sebab banyak didapati kondisi umum dalam ayat tertentu kemudian dijeaskan detail oleh ayat yang lain .

2. Alternatif kedua ketika tidak dijumpai ayat lain yang menjelaskan, mufassir harus meneilisik Sunnah yang merupakan Penjelasan Al-Qur'an. Bahkan imam Syafi’I, seperti ditulis Ibnu Katsir mengungkapkan, "Setiap hukum yang ditetapkan Rasulullah merupakan hasil pemahamanya terhadap Al-Qur'an.

3. Selanjutnya jika permasalahan suatu ayat yang masih belum jelas dalam konteks tidak ditemukan penjelasan mulai dari al-Qur'an dan Hadis, maka hal tersebut bisa

\footnotetext{
${ }^{18}$ Imam Ibnu Katsir,s Tafsir Al-Qur'anul Adzim "Ibnu Katsir” Jilid 2 dan 3, (Jawa Tengah: Insan Kamil, Cetke.4, 2017), hlm. 6 -7

${ }^{19}$ Abd. Al-Hayy Al-Farmawi, Suatu Pengantar Metode Tafsir Maudhu'I, (Bandung: Pustaka Setia, 2002), hlm. 23

${ }^{20}$ Imam Ibnu Katsir, Tafsir Al-Qur'anul Adzim “Ibnu Katsir” Jilid 1, (Jawa Tengah: Insan Kamil, Cet-ke.4, 2017), hlm.32
}

Falasifa, Vol. 10 Nomor 2 September 2019 | 153 
Wely Dozan

melihat konsep-konsep atau pendapat para sahabat yang telah menafsirkan ayat alQur'an. $^{21}$

Hal tersebut dilakukan Ibnu Katsir untuk mendapatkan proses pemahaman bukan proses penyusunan. Karena pemahaman telah berakhir dengan sebuah konklusi intlektual yang sangat terbuka. ${ }^{22}$ Dengan demikian tafsir dengan metode analisis ini relatif memberikan kesempatan yang luas kepada mufassir untuk mencurahkan ide-ide dan gagasanya dalam menafsirkan al-Qur'an. Ini berarti bahwa metodologi tahili yang dipakai oleh ibnu katsir dapat memberikan para mufassir untuk membuka pintu seleabarnya untuk mengemukakan pemikiranya terkait penafsiran al-Qur'an. ${ }^{23}$ Adapun kitab yang mempunyai ciri-ciri metode Tahlili diantaranya: Jami al-Bayan an Ta'wil Ayi Al-Qur'an karangan Ibn Jarir al-Thabari (w.310 H.), Ma'alim al-Tazil karangan al-Bagdhawi (w. 516 H.), Tafsir Al-Quran al-Adzim karangan Ibnu Katsir (w. 774 H.), dan Addur al-Mantsur fi al-tafsir bi al-Ma'tsur karangan al-Suyuthi (w. 911 H.). ${ }^{24}$

\section{Epistemologi Metodologi Tafsir Ibnu Katsir}

Pada Pembahasan ini, penulis akan merekonstruksi pengetahuan (epistemology) metodologi penafsiran Ibnu Katsir dalam menafsirakan teks-teks ayat al-Qur'an . Adapun konsep dasar dari pembahasan epistemology yaitu mengacu Kepada cabang filsafat yang mempelajari teori pengetahuan manusia khususnya pada empat masalah yaitu: Pertama, Sumber-sumber Ilmu Pengetahuan, Kedua, Alat Pencapaian Pengetahuan, Ketiga, metode pencapaian pengetahuan. Keempat, batasan pengetahuan atau klasifikasi pengetahuan. ${ }^{25}$ Maka hal tersebut ada kaitanya terhadap penafsiran Ibnu Katsir yang selama menafsirkan ayat-ayat al-Qur'an secara panjang dan luas. Jika ditelusuri perkembangan tafsir ALQur'an melalui metode Tahlili (analitis) mengandung beberapa aspek penafsiran dianytaranya: pertama, Tafsir bi Al-Ma’tsur dan tafsir Al-Ra'yi.

\footnotetext{
${ }^{21}$ Mani' Abd Halim Mahmus, Metodologi Tafsir Kajian Komprehensif Metode Para Ahli Tafsir..., hlm. 60

${ }^{22}$ Rohimi, Metodologi Ilmu Tafsir dan Aplikasi Model Penafsiran, ( Yogyakarta: Pustaka Pelajar, 2007), hlm.60

${ }^{23}$ Nasaruddin Baidhan, Metodologi Penafsiran Al-Qur'an, (Yogyakarta: Pustaka Pelajar, 2005), hlm. 32

${ }^{24}$ Baca Selengkapnya, Nasaruddin Baidhan, Metodologi Penafsiran Al-Qur'an, (Yogyakarta: Pustaka Pelajar, 2005), hlm. 32

${ }^{25}$ Ayi Sopyan, Kapita Selekta Filsafat, (Bandung: Pustaka Setia,2010), hlm. 212

Falasifa, Vol. 10 Nomor 2 September 2019| 154
} 


\section{Tafsir Bi Al-Ma'tsur}

Tafsir bi al-Ma'tsur adalah penjelasan Al-Qur'an sendiri dari Rasulullah SAW yang disampaikan kepada para Sahabat, dari para sahabat berdasarkan ijtihadnya, dan dari para tabi'in juga berdasarkan ijtihadnya. Adapun fase-fase dalam tafsir bi al-Matsur ini dilakukan melalui dua fase diantaranya: Pertama, fase periwayatan. Pada fase ini, para sahabat menuqil riwayat penafsiran dari Nabi dan meyampaikanya kepada sahabat lainya. Para tabi'in menukil riwayat dari para sahabat dengan metode penukilan berupa sanad yang teliti dan seksama. Fase ini berakhir dengan datangnya pase kedua.. Kedua, fase fase pengodifikasian. Pada fase ini, riwayat-riwayat penafsiran yang disebarkan kitab hadis yang kemudian sebagaimana telah dijelaskan berdiri sendiri sebagai sebuah disiplin ilmu ${ }^{26}$. Hal ini Ibnu katsir dalam menafsirkan ayat al-Qur'an didukung dengan pengetahuan hadishadis Rasulullah Saw. Dengan demikian, sumber tafsir bil ma'tsur ada tiga diantaranya:
a. Al-Qur'an al Karim.
b. Sunah Nabawiyyah yang shahih.
c. Pendapat para sahabat.
d. Pendapat para tabi'in.

Pendek kata penulis akan memberikan sumber pengetahuan atau epistemology penafsiran Ibnu Katsir dalam menafsirka ayat-ayat al-Qur'an sebagai salah contoh:

1. Contoh Penafsiran Al-Qur'an dengan Al-Qur'an yaitu penafsiran kata "kalimat" di dalam firman Allah : "Lalu adam menerima kalimat dari Tuhanya, lalu dia menerima taubatnya. (Q.S. Al-Baqarah: 37), yang ditafsirkan dengan firman Allah: "Kedua Berkata: Wahai Tuhan kami, kami telah menganiaya diri kami sendiri, dan jika engkau tidak mengampuni kami, niscaya kami akan menjadi orang-orang yang merugi. (Q.S. AL-A'raf: 23). Hal ini menururt pendapat sebagaian ulama .

2. Penafsiran Rasulullah Saw. Terhadap kata "al-dhulm" dengan "syirik", yaitu dalam firman Allah Swt " Yaitu orang-orang yang beriman dan tidak mencampur adukkan keimanan mereka denagn kezaliman. ${ }^{27}$

\footnotetext{
${ }^{26}$ Abd. Al-Hayy Al-Farmawi, Suatu Pengantar Metode Tafsir Maudhu'I..,hlm. 24-25

${ }^{27}$ Yunus Hasan Abidu, Tafsir Al-Qur'an "Sejarah Tafsir dan Metode Para Mufassir, (Jakarta: Gaya Media Peratama, 2007), hlm. 5
} 
Wely Dozan

3. Penafsiran para sahabat yaitu dengan salah satu contoh. Yang dimana Rasulullah Saw bersabda yang artinya: "Ya Allah, faqihkanlah ia dalam urusan agama, dan ajarkanlah kepadanya ta'wil. Ibnu Jarir At-Thabari berkata " Sebaik-baik penerjemah adalah Ibnu Abbas" Demikian juga Ibnu jarir meriwayatkanya dari Bin-dar, dari Ja' far bin 'Aun, dari Al-A'masy dengan redaksi yang sama. ${ }^{28}$

\section{Tafsir Bil Ra'yi (Tafsir Bil Dirrayah)}

Tafsir bil ra'yi berarati menafsirkan al-Qur'an dengan ijtihad setelah mufassir memahami bahasa Arab, menguasai makna-maknanya. ${ }^{29}$ sehingga dalam penafsiranya konsep ra’yu yang digunakan oleh Ibnu Katsir dalam memahami ayat al-Qur'an harus didasarkan dengan adanya ilmu pengetahuan. Sesungguhnya barang siapa yang berkata tentang al-Qur'an dengan pendapatnya sendiri, sungguh ia telah membebani dirinya dengan suatu yang tidak diketahuinya dan menempuh jalan yang tidak diperintahkan. ${ }^{30}$ Dengan deikian penaaran rasionaloitas yang digunakan Ibnu Katsir dalam menafsirkan ayat-ayat alQur'an menggunakan berbagai uslub gaya kebahsaan yang diapakai diantaranya: Pertama, Bahasa Arab, karena ilmu bahasa dan konjungsi agar dapat memahami makna kata-kata dalam al-Qur'an sesuai dengan makna asalnya, mengenal maknanya ketika al-Qur'an turun, dan harus menelaah secara luas kamus-kamus agar dapat mengetahui sinonim, homonim dan yang sejenisnya. Kedua, Ilmu Nahwu dan Sharaf. Dengan ilmu ini dapat mengetahui susunan dan bentuk kata dalam al-Qur'an.

Ketiga, Adab dan ilmu balaghah, yakni, bayan, ma'ani, dan badi' karena al-Qur'an turun dengan gara bahasa Arab yang fasih dan menantang dengan mereka kemukjizatanya agar ia mampu menangkap kalimat-kalimat khusus dan aspek-aspek keindahannya, agar dapat memahami al-Qur'an dengan benar. Keempat, ilmu-ilmu al-Qur'an. Seyogyanya mufassir memiliki pengetahuan yang luas dalam bidang ilmu-ilmu dasar yang berkaitan langsung dengan al-Qur'an dan penguasaanya dengan baik. Seperti ilmu qira'at, ilmu asbab nuzul, pengetahuan tentang ilmu maki dan madani, muhkam dan mutasyabih, 'am dank has, nasihk-mansukh dan lain-lain. Semua itu dapat membantunya memahami makna-makna al-

\footnotetext{
${ }^{28}$ Imam Ibnu Katsir, Tafsir Al-Qur'anul Adzim "Ibnu Katsir" Jilid 1, (Jawa Tengah: Insan Kamil, Cet-ke.4, 2017), hlm.34

${ }^{29}$ unus Hasan Abidu, Tafsir Al-Qur'an 'Sejarah Tafsir dan Metode Para Mufassir...,hlm. 8

${ }^{30}$ Ibnu Katsir, Tafsir Al-Quranul Adzim..., hlm.32

Falasifa, Vol. 10 Nomor 2 September 2019| 156
} 
Epistemologi Tafsir Klasik: Studi Analisis ...

Qur'an dan menjaganya dari terpleset tidak samar lagi bahwa wajib bagi mufassir untuk menghafal seluruh teks al-Qur'an agar ia mampu memahaminya dengan sebenar-benarnya. Kelima. Ilmu ushuluddin dan tauhid. Hal ini dapat membuat mufassir mampu memahami dasarOdasar akidah Islam, seperti mengetahui yang wajib bagi Allah Swt dan hal-hal yang wajib baginya. Keenam, ilmu ushul fiqh. Ilmu ini merupakan keniscayaan bagi mufassir sebagaimana niscaya bagi setiap ilmu fiqih agar terjaga dari kesalahan menggali hukum syara' dari ayat-ayat al-Qur'an dan menolongnya dari aspek-aspek argumentasi dari teks dan menentukan kaidah-kaidah penggalian hukm. Ilmu ushul fiqh mengharuskan seorang mufassir untuk memahami fiqh dan mengetahui hokum-hukumnya dan mengetahui cara pengistinbatanya. Ketujuh, Hadits dan ilmu-ilmunya, merupakan suatu kewajiban bagi mufasssir untuk memahami sunnah Rasul saw. Baik dari segi riwayat maupun dirayah agar ia mampu menguasai tafsir bil ma'tsur, mengetahui sunah yang merinci ke-mujmal-an alQur'an, sunah yang menjelaskan ke-mubham al-Qur'an dan dibantu dengan ilmu-ilmu yang lainya. $^{31}$

\section{Skema Epistemologi Metodologi Tafsir Ibnu Katsir}

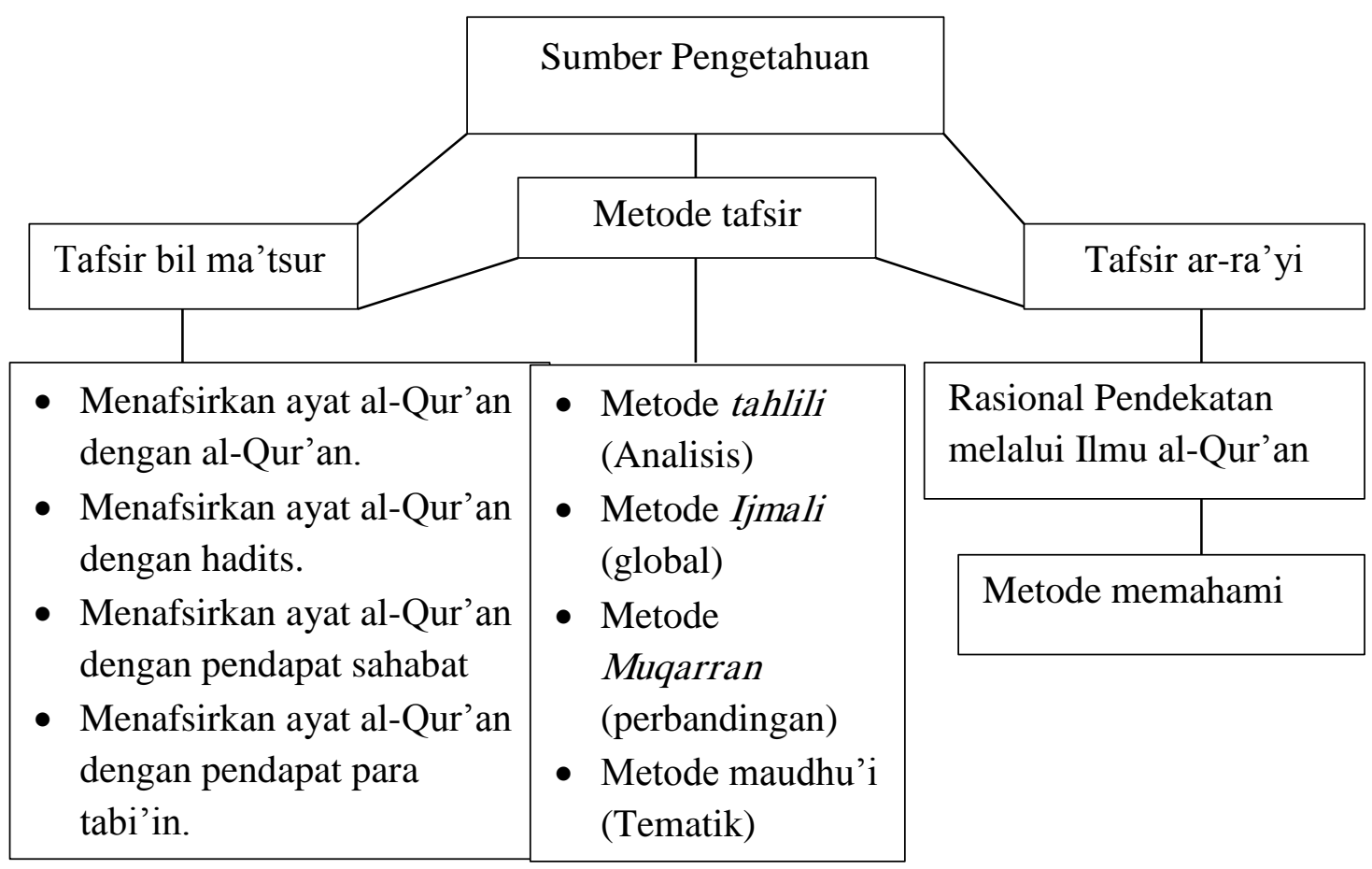

${ }^{31}$ Yunus Hasan Abidu, Tafsir Al-Qur'an Sejarah Tafsir dan Metode Para Mufassir...,hlm. xxiv-xxv Falasifa, Vol. 10 Nomor 2 September 2019 | 157 
Wely Dozan

Tampak dengan jelas di dalam skema di atas menunjukkan epistemologi metodologi tafsir yang digunakan dalam menafsirkan al-Qur'an hal tersbeut yang menjadi akar-akar dalam menafsirkan al-Qur'an. Dengan demikian tafsir bil ma'tsur dan tafsir bi al-ra'yi, niscaya tak akan dapat mencapai salah satu corak penafsiran tanpa memakai salah satu dari empat metode penafsiran itu. Sehingga secara umum penafsiran klasik dituntut secara utlak agar menguasai ilmu metode tersebut. Pendek kata epistemologi metodologi tafsir menduduki posisi yang teramat penting di dalam sekaligus proses pengetahuan yang menjadi salah satu alat dalam mengungkapkan makna teks ayat-ayat al-ur'an tersebut. ${ }^{32}$

\section{KESIMPULAN}

Berdasarkan uraian diatas bahwa, tafsir merupakan alat yang digunkan oleh para mufassir untuk menjelaskan dan mengungkapkan ayat-ayat al-Qur'an. Penjelasan tersebut tidak pernah terlepas dari sebuah perangkat metodologi yang merupakan salah satu ciri sebagai basis pengetahuan sebagai dasar-dasar untuk memahami ayat al-Qur'an. Hal tersebut menunjukkan ada beberapa klasifikasi epistemologi tafsir ibnu katsir diantaranya: Pertama, Tafsir bil ma'tsur yang memiliki cabang pengetahuanya diantaranya, menafsirkan dengan ayat al-Qur'an, menafsirkan al-Qur'an dengan Hadits, menafsirkan al-Qur'an dengan pendapat para sahabat, menafsirkan al-Qur'an dengan pendapat para tabi'in. Kedua, tafsir ar-ra'yi yaitu menafsirkan al-Qur'an dengan rasional yang tentu merupakan dari hasil pengetahuan kaitanya dengan ilmu-ilmu al-Qur'an. Proses tersebut dihasilkan oleh ibnu katsir melalui metode analisis tahlili yang penjelasanya secara terperici melalui dari pengungkapan aspek asbabun nuzul, aayat maki dan madani, melihat nasikh-mansukh-Nya dan sebagainya. Oleh karenya, epistemologi tafsir ibnu ibnu katsir dalam kitabnya tafsir alQur'anul adzim yang merupakan kitab tafsir yang menjelaskan ayat-ayat al-Qur'an melalui beberapa sumber pengetahuan sebagai alat metodologi untuk mengungkapkan makna yang terkandung di dalam subtansi al-Qur'an tersebut.

\section{DAFTAR PUSTAKA}

H.A. ATHILLAH, Sejarah al-Qur'an, Verifikasi Tentang Ptensitas al-Qur'an, Yogyakarta: Pustaka Pelajar, 2010.

\footnotetext{
${ }^{32}$ Nasaruddin Baidan, Metodologi Penafsiran al-Qur'an...,hlm.9-10

Falasifa, Vol. 10 Nomor 2 September 2019| 158
} 
Epistemologi Tafsir Klasik: Studi Analisis ...

Abdul Mustaqim, Metode Penelitian Al-Qur'an dan Tafsir, Yogyakarta: Idea Press, 2015.

Yayan Rahtikawati, Dadan Rusma, Metodologi Tafsir Al-Qur'an (Strykturalisme, Semantik, Semiotik, \& hermeneutic, Bnadung: Pustaka Setis, 2013.

Abdul Mustaqim, Metode Penelitian Al-Qur'an dan Tafsir, Yogyakarta: Idea Press, 2018.

Abdul Mustaqim, Dinamika Sejarah Tafsir Al-Qur'an (Studi Aliran-aliran Tafsir dari Periode Klasik, Pertengahan hingga Moderen-Kontemporer), Yogyakarta: Ida Press, 2016.

Rohimi, Metodologi Ilmu Tafsir dan Aplikasi Model Penafsiran, Yogyakarta: Pustaka Pelajar, 2007.

Mani' Abd Halim Mahmud, Metodologi Tafsir "Kajian Komprehensif Metode Para Ahli Tafsir" Jakarta: Raja Grafindo, 2006.

Imam Ibnu Katsir, Tafsir Al-Qur'anul Adzim "Ibnu Katsir" Jilid 1, Jawa Tengah: Insan Kamil, Cet-ke.4, 2017.

Nasaruddin Baidan, Metodologi Penafsiran Al-Qur'an, Yogyakarta: Pustaka Pelajar, Cetke.III, 2005.

Kementerian Agama RI, Ar-Rahim (Al-Qur'an dan Terjemahanya), Bandung: CV Mikraj Khazanah Ilmu, 2016.

Imam As-Syuthi, Asbabun Nuzul Qur'an, Tahqiq: Syaikh Hafizh Syi'sya Jawa Tengah: Insan Kamil, 2016.

Abd. Al-Hayy Al-Farmawi, Suatu Pengantar Metode Tafsir Maudhu'I, Bandung: Pustaka Setia, 2002.

Rohimi, Metodologi Ilmu Tafsir dan Aplikasi Model Penafsiran, Yogyakarta: Pustaka Pelajar, 2007.

Nasaruddin Baidhan, Metodologi Penafsiran Al-Qur'an, Yogyakarta: Pustaka Pelajar, 2005.

Ayi Sopyan, Kapita Selekta Filsafat, Bandung: Pustaka Setia,2010.

Yunus Hasan Abidu, Tafsir Al-Qur'an "Sejarah Tafsir dan Metode Para Mufassir, Jakarta: Gaya Media Peratama, 2007. 